\title{
Application of Adaptive Neuro-fuzzy Inference System (ANFIS) for Prediction of Nutrients (Nitrogen, Phosphorus, Potassium and Magnesium) level from Soil Sample in some States of Nigeria Vegetational Zone.
}

\author{
Abdullahi Yusuf Egwoh ${ }^{1}$, Emmanuel Amano Onibere ${ }^{2}$, Philip Odion ${ }^{3}$ \\ Department of Computer Science Nigeria Defence Academy, Kaduna ${ }^{1,2,3}$
}

\begin{abstract}
Lack of soil nutrients knowledge can cause serious yield challenges if remains undiagnosed, misdiagnosed and untreated. It is the most prevalent problem identified by Nigeria Agricultural Development Project (ADP) to be affecting majority of the productive adult farmers in Nigeria. This study identified and compare qualitative and quantitative decision methods. Soil laboratory were used for determine soil nutrients level. This research proposes a hybrid soft computing model driven, by complimenting the advantages of Artificial Neural Network (ANN) and Fuzzy Logic (FL) with the use of Adaptive Neuro Fuzzy Inference System (ANFIS) for predicting the soil nutrients level. The Matrix Laboratory (matlab) applications were used for the analysis. The results of the analysis were found to be within acceptable predefined limits as examined by ADP officials. Evaluation of the model using standard statistical methods proved that the model is effective in providing accurate soil nutrients level $\left(\mathrm{R}^{2}\right.$ of $\left.94 \%\right)$. The Root Means Square Error (RMSE) from ANFIS simulation is very low (0.000162) which indicate the significant and effectiveness of the model for prediction.
\end{abstract}

Keywords: Adaptive Neuro Fuzzy Inference System (ANFIS), Soil formation, Triangular membership function and Rule Viewer.

\section{INTRODUCTION}

\section{Soil Formation}

Soil is an important component of the Earth's ecosystem (Dominati et al., 2010). The world's ecosystems are impacted in far-reaching ways by the processes carried out in the soil, from ozone depletion and global warming, to rainforest destruction and water pollution. With respect to Earth's carbon cycle, soil is a major carbon reservoir, and it is potentially one of the most reactive to human disturbance and climate change (Dominati et al., 2010) . As the planet warms, it has been predicted that soils will add carbon dioxide to the atmosphere due to increased biological activity at higher temperatures, a positive feedback (amplification) (Torsvik and Ovreas 2002). This prediction has, however, been questioned on consideration of more recent knowledge on soil carbon (Torsvik and Ovreas 2002) .

Soil acts as an important medium, a habitat for soil organisms, a recycling system for nutrients and organic wastes, a regulator of water quality, a modifier of atmospheric composition, and a medium for plant growth, making it a critically important provider of ecosystem services (Ponge J F, 2015). Since soil has a tremendous range of available niches and habitats, it contains most of the Earth's genetic diversity . A gram of soil can contain billions of organisms, belonging to thousands of species, mostly microbial and in the main still unexplored (Torsvik and Ovreas 2002) . Soil has a mean prokaryotic density of roughly $10^{8}$ organisms per gram, whereas the ocean has no more than $10^{7}$ prokaryotic organisms per milliliter (gram) of seawater (Denmead and Shaw 2017) . Organic carbon held in soil is eventually returned to the atmosphere through the process of respiration carried out by heterotrophic organisms, but a substantial part is retained in the soil in the form of soil organic matter; tillage usually increases the rate of soil respiration, leading to the depletion of soil organic matter (Schlesinger and Andrews 2000). As long as plant roots need oxygen, ventilation should be an important characteristic of soil. This ventilation can be accomplished via networks of interconnected soil pores, which also absorb and hold rainwater making it readily available for uptake by plants. Since plants require a nearly net release of continuous supply of water, but most regions receive sporadic rainfall, the water-holding capacity of soils is vital for plant survival (Denmead and Shaw 2017). Soils can effectively remove impurities, kill disease agents and degrade contaminants, this latter property being called natural attenuation (Bronick and Lal 2005) . Typically, soils maintain a net absorption of oxygen and methane, and undergo a carbon dioxide and nitrous oxide (Schlesinger and Andrews 


\section{International Journal of Advanced Research in Computer and Communication Engineering}

Vol. 9, Issue 10, October 2020

\section{DOI 10.17148/IJARCCE.2020.91012}

2000) . Soils offer plants physical support, air, water, temperature moderation, nutrients, and protection from toxins (Torbert et al., 1992). Soils give readily available nutrients to plants and animals by transforming dead organic matter into various nutrient forms. A typical soil is about $50 \%$ solids (45\% mineral and 5\% organic matter), and $50 \%$ voids of which half is occupied by water and half by gas (Ponge J F, 2015). The percent soil mineral and organic content can be treated as a constant (in the short term), while the percent soil water and gas content is considered highly variable whereby a rise in one is simultaneously balanced by a reduction in the other (Schlesinger and Andrews 2000) . The pore space allows for the infiltration and movement of air and water, both of which are critical for life in soil (Torbert et al., 1992) . Compaction, a common problem with soils, reduces this space, preventing air and water from reaching plant roots and soil organisms (Torbert et al., 1992) .

Soils supply plants with nutrients, most of which are held in place by particles of clay and organic matter (colloids) (Ponge J F, 2015). The nutrients may be adsorbed on clay mineral surfaces, bound within clay minerals (absorbed), or bound within organic compounds as part of the living organisms or dead soil organic matter (Ponge J F, 2015) . These bound nutrients interact with soil water to buffer the soil solution composition (attenuate changes in the soil solution) as soils wet up or dry out, as plants take up nutrients, as salts are leached, or as acids or alkalis are added (Schlesinger and Andrews 2000).

Most plant nutrients, apart from nitrogen, originate from the minerals that make up the soil parent material. Very small percentage of nitrogen originates from rain as dilute nitric acid and ammonia, while majority of the nitrogen is present in soils as a result of nitrogen fixation by bacteria (Torbert et al., 1992). Once in the soil-plant system, most nutrients are recycled through living organisms, plant and microbial residues (soil organic matter), mineral-bound forms, and the soil solution. Both living microorganisms and soil organic matter are very essential to this recycling, and thereby to soil formation and soil fertility (Ponge J F, 2015).

\section{Adaptive Neuro Fuzzy Inference System (ANFIS)}

Fusion or hybrid methods are advancement in soft computing, which combines two different soft computing techniques to improve system performance and offsets the disadvantages of one by the advantages of the other method. ANFIS, which is combination of fuzzy logic with ANN, is one of the successful examples of hybrid soft computing method that has a wide use in different modeling fields (Jain and Martin, 1998; Huang et al., 2010).

Fuzzy logic models use approximate reasoning (IF-THEN) rules, which works like human decision making "rule of thumb." The final product is a graded statement rather than strict results such as true or false (Jang et al., 1997; Sendren and $\mathrm{Xu}$ 2007).

The diagrammatical description of how the general structure of ANFIS from input (Phosphorous, Potassium, Nitrogen and Magnesium) to output Soil nutrient level (Very low, Low, Medium, High and Very high) should look like is shown below

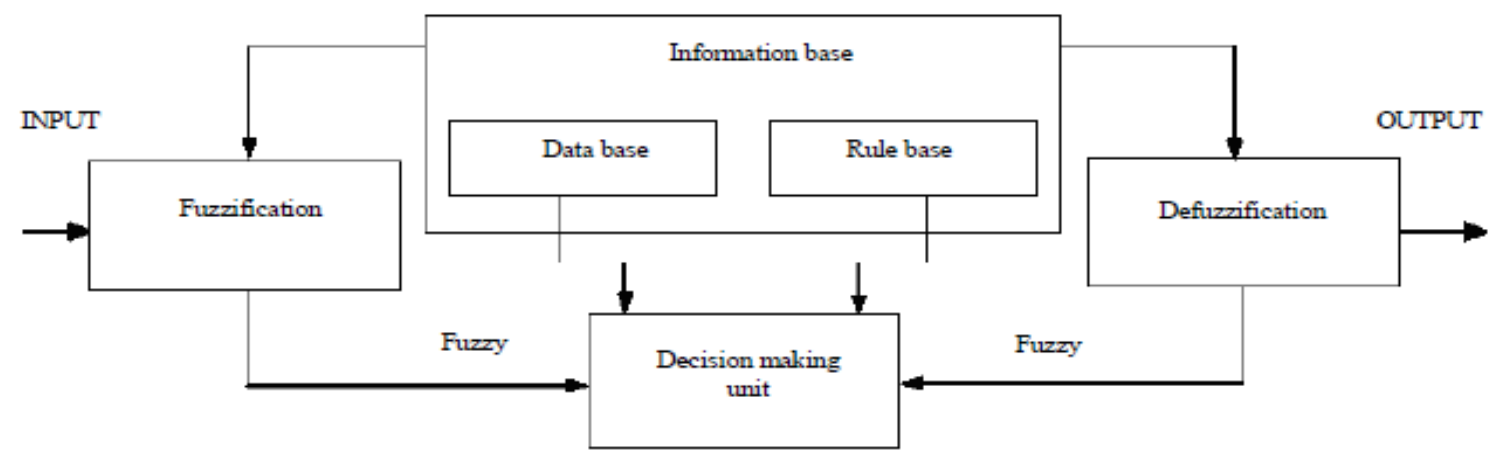

General Structure of the ANFIS (Saad et al., 2014)

\section{LITERATURE REVIEW}

Fuzzy inference systems were used as alternative to statistical tool for developing predictive models to estimate the needed parameters which have been successfully applied to solve different problems in soil applications (Mcbratney et al., 1997) . Aali et al (2009) used an ANFIS for estimation of saturation percentage of soils collected from Boukan region in the north-western part of Iran and Percent clay, silt, sand and organic carbons were used as inputs . The results showed that ANFIS model can be used for reasonable estimation of saturation percentage values of soils . Bektas and Ozgan (2010) developed a model using ANFIS technique to predict the particle diameter of soil for different cases without the need for a test. The quantities of the sodium hexametaphosphate and the hydrometer reading times were used as inputs in the model. Test results and predicted outcomes were compared and high correlations were obtained . Sezer et al (2010) employed an ANFIS to predict sand permeability and the result was very significant . In comparison with 


\section{International Journal of Advanced Research in Computer and Communication Engineering}

Vol. 9, Issue 10, October 2020

\section{DOI 10.17148/IJARCCE.2020.91012}

nonlinear multiple regression analyses results, it was revealed that ANFIS structure was comparatively successful in the prediction of the permeability utilizing particle shape and grain size distribution information .

Hashemi, (2018) proposed modeling unsaturated soils shear strength using Adaptive Neuro fuzzy inference system and this study was compared with other methods and ANFIS method outperformed other methods . Tiwari (2017) proposed modelling of infiltration of soil using ANFIS and the results suggests that Gaussian membership function of ANFIS works better. Al-Sulaiman (2015) applied an ANFIS for prediction of unsaturated soil hydraulic conductivity $(\mathrm{ku})$. The unsaturated hydraulic conductivity of soil $(\mathrm{ku})$ is one of the most principal parameters in the study of water movement in the soil and the ANFIS perform better result in modelling .

Mokarram, (2017) proposed the prediction of soil fertility for wheat cultivation. In this study, three methods were used for the prediction and ANFIS gives better prediction. Saad and Hemed (2014) proposed the prediction of soil fractions (sand, silt and clay) in surface layer based on natural radionuclides concentration in the soil using ANFIS . ANFIS prediction was rated the best compared to other method . Abdulwahed (2016) proposed modelling of sodium absorption ratio of the soil using ANFIS and the result of this study shows the effectiveness of the ANFIS for the modeling . Rahnema (2018) proposed the prediction of effective stress parameter of unsaturated soils using ANFIS and the study reveals that ANFIS prediction was the best compared to other methods .

The learning capability of neural network and capability of fuzzy logic to deal with vagueness lends a hand in accepting the hybrid neuro-fuzzy methodology as one of the best alternative for solution of problems in these fields . Thus, this study explores the potential of ANFIS in the prediction of ( $, \mathrm{P}, \mathrm{K}, \mathrm{Mg}$ ) from humus, silt and loam soil.

\section{METHODOLOGY}

\section{Data Acquisition}

Data is an important component for any system. For an intelligent system, knowledge of the data to be used is very paramount. Therefore, data on these Nutrients; Phosphorous (P), Nitrogen (N), Potassium (K) and Magnesium (Mg) was collected for the analysis. A cross-sectional survey was conducted to estimate soil nutrients $(\mathrm{P}, \mathrm{N}, \mathrm{K}$, and $\mathrm{Mg})$ in the selected States (Kaduna, Niger, Benue and Ondo) of some vegetation zone of Nigeria. This survey was conducted using a multi-stage stratified sampling method. In the first phase, Three LGA was randomly selected in each state. In the second phase, a random district was selected in each LGA and ten different samples of soil were taken. In the third stage, the one hundred and twenty (120) cultivated soil location (10 per LGA multiply by 12 LGA from 4 States) which was randomly sampled and taken for soil testing and soil particles analysis which was determined in the soil science laboratory at Federal University of Technology Minna, Niger State of Nigeria. These soil test result were used for the analysis in this study.

\section{DATA ANALYSIS AND TESTING}

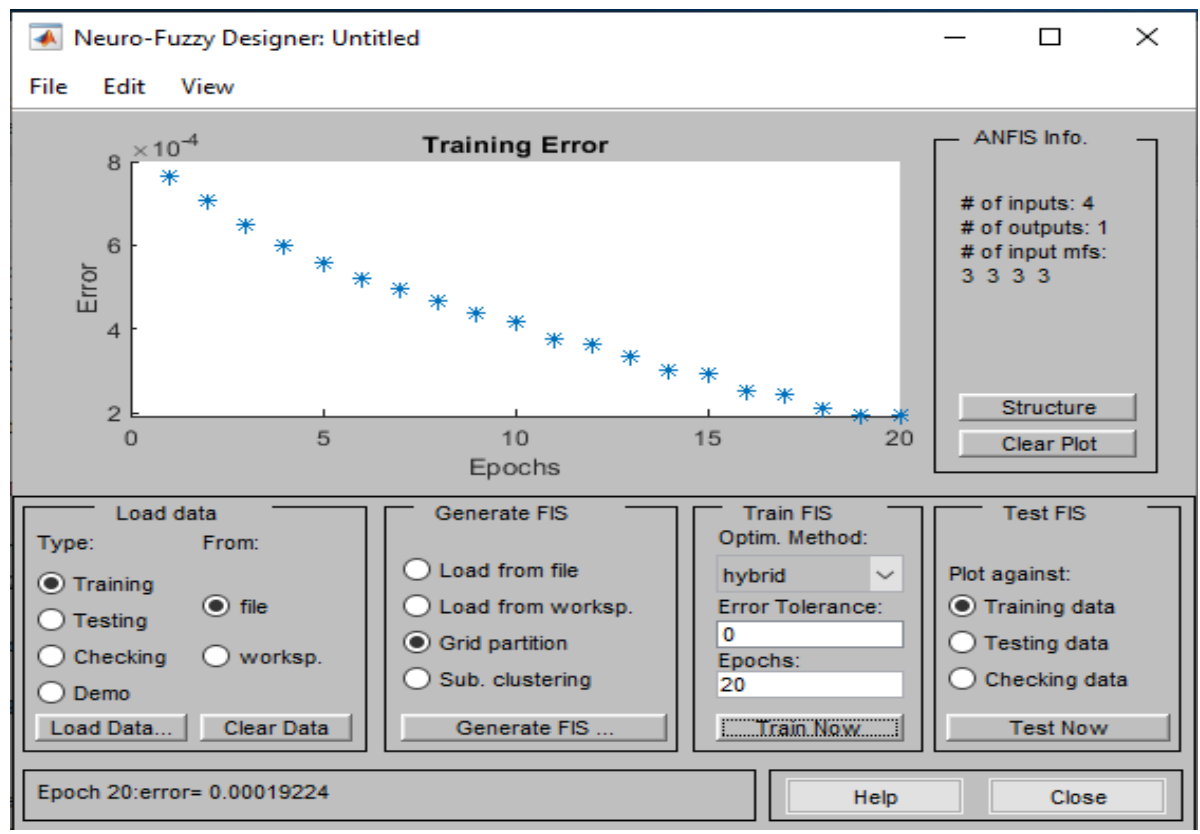

Figure 1: Training Error Performance (Triangular) 


\section{International Journal of Advanced Research in Computer and Communication Engineering}

Vol. 9, Issue 10, October 2020

\section{DOI 10.17148/IJARCCE.2020.91012}

The 120 data were used for the training and testing. There are four inputs and one output for the system. The training and checking data consisted of variations in the soil test output corresponding to the values of the four inputs ( N, P, K and $\mathrm{Mg}$ ). The correctness and adjustments in the MFs is calculated and the FIS is trained by the network. In implementing the ANFIS model, the type of MF, linguistic variables and number of rules may have been determined apriori. The model analyzes one type of MFs; Triangular. ANFIS extracts rules where the premises are connected through differentiable tnorms and generates as many rules as the product of the number of linguistic terms per variable. Experiments were carried out using MatLab version 2018b running on Laptop (2.0 GHz, 8GB RAM, 64-bit MS Windows 7). The dataset is split into two subsets: training set $(60 \%)$ and testing set $(40 \%)$. The data set comprises of different features (nutrients and their linguistic labels) and therefore was trained to produce a stable convergence. The performance index and Mean Square Error (MSE) were measured. Each combination was used to test for the predictive accuracy. Several experiments were performed to obtain a learning error rate for which the value of the RMSE becomes a minimum. In triangular MF, the learning error rate was varied from an initial value of 0.00019 to 0.00016 . It was observed that at 0.000162 the root mean square error become minimum and the maximum number of iterations is restricted to 20 epochs. Triangular MF performs better since the RMSE is very small. As shown in Figure 1.

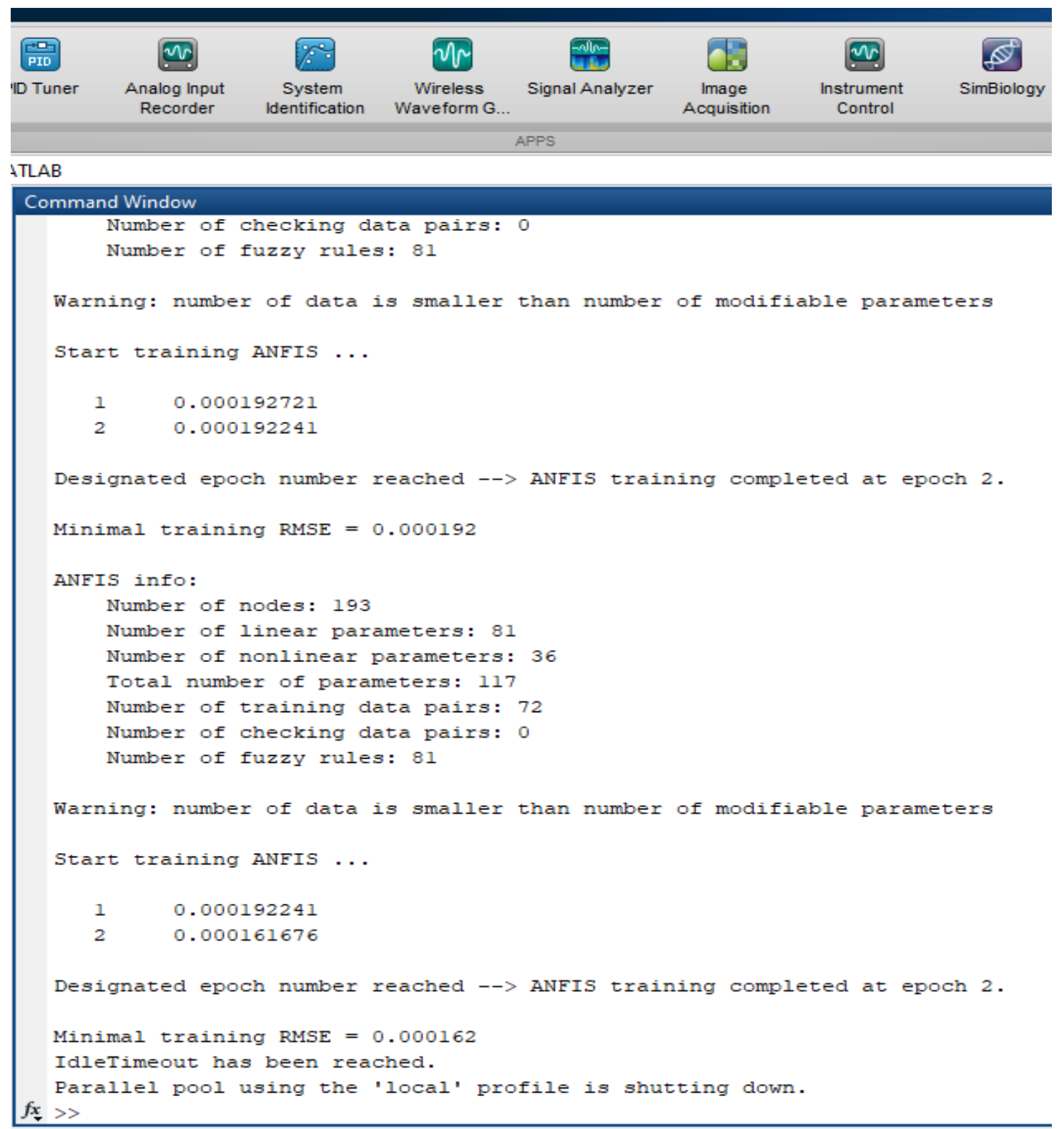

Figure 2: Linearity Check (Triangular) 
The RMSE is minimal at 0.000162 while the epochs is 20 as shown in Figure1.The linearity checks show that about $70 \%$ parameters are linear while $30 \%$ are nonlinear, it shows the prediction based on this model is very effective as shown in Figure 2.

After the tuning of the FIS is completed, the performance of the system is checked using 20 test scenarios whose results were obtained from the domain. It is observed that RMSE is very small (0.000162). It shows the model efficiency in prediction of the nutrients using triangular method.

\section{RULE VIEWER}

The rule viewer displays the whole FIS which is based on Soil test level. In Figure 3, the five plots across the top of the figure represent the antecedents and consequent of the rules. Each rule is a row of plots and each column is a variable. The rule numbers are displayed on the left of each row . For instance, if a soil test $\mathrm{N}$ of 0.5 with $\mathrm{P}$ of 0.635 , $\mathrm{K}$ of 0.5 and $\mathrm{Mg}$ of 0.5 is inputted, a Soil test level value (output) of 0.539 is produced and rule number 30 is fired as as shown in figure 3.

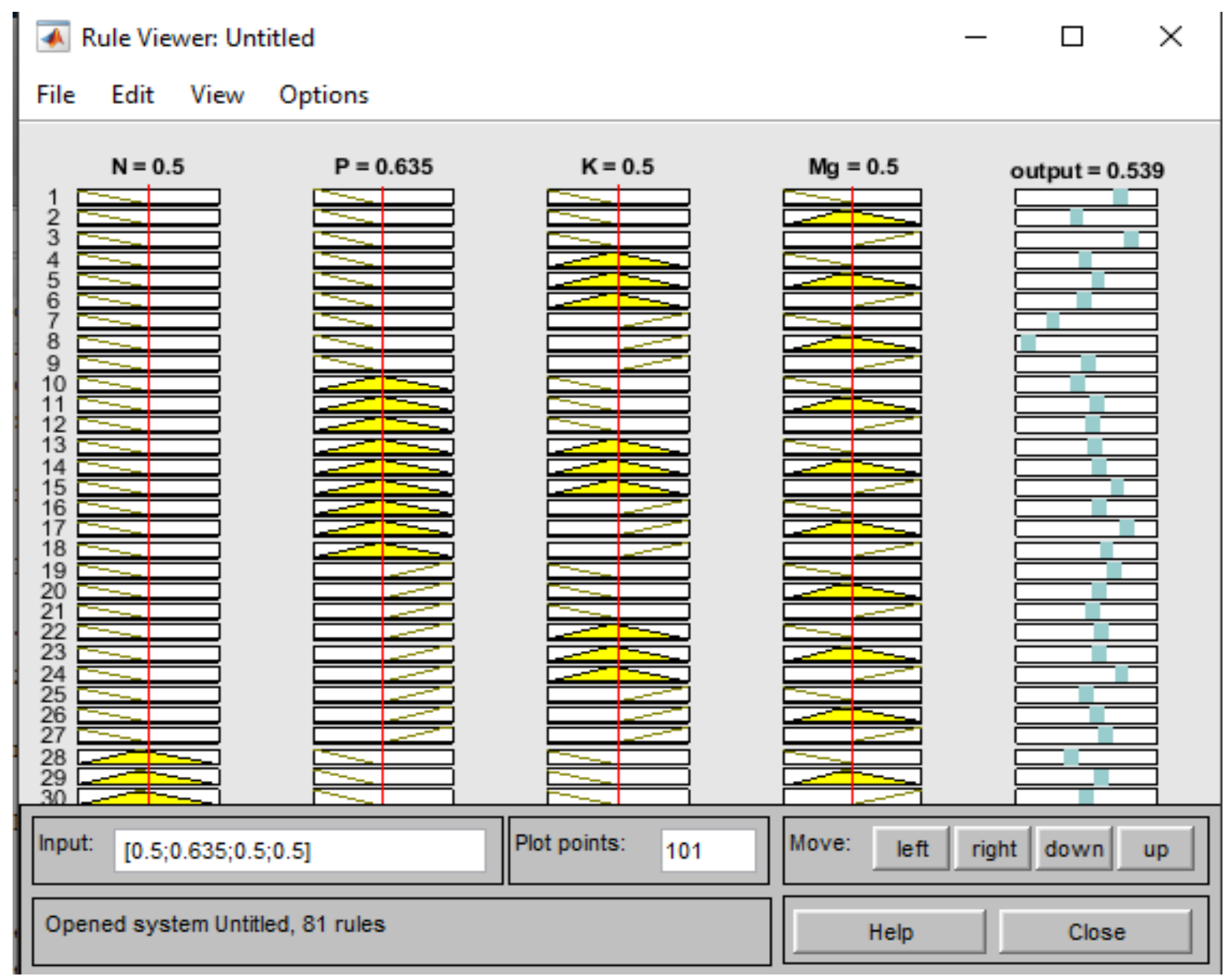

Figure 3: Rule Viewer with specific values

Because the rule viewer shows one calculation at a time of Soil test level, it was used to generate the FIS results. The rule viewer allows for a complete interpretation of the entire FIS at once.

The coefficient of determination is very high (94\%). This indicates the efficiency of the model for prediction of the nutrients $(\mathrm{N}, \mathrm{P}, \mathrm{K}$, and $\mathrm{Mg}$ ). The error of the estimate is 0.03404 , which is very low as shown in table 1 .

Table 1: Coefficient of determination output

Model Summary

\begin{tabular}{lr|r|r|r} 
Model & R & R Square & Adjusted R Square & Std. Error of the Estimate \\
\hline 1 & $.968^{\mathrm{a}}$ & .938 & .921 & .03404 \\
\hline
\end{tabular}

a. Predictors: (Constant), Mg, K, P, N 


\section{International Journal of Advanced Research in Computer and Communication Engineering}

Vol. 9, Issue 10, October 2020

\section{DOI 10.17148/IJARCCE.2020.91012}

\section{CONCLUSION}

For the one hundred and twenty (120) test cases considered the model performed better with a prediction efficiency of 94\%. The ANFIS simulation result shows the prediction efficiency of the model (RMSE of 0.000162). The estimated error for the coefficient of determination is very small too (0.03404). It is generally observed that ANFIS is very efficient in prediction of soil nutrients level.

\section{REFERENCES}

[1]. Aali, K.A., Parsinejad, M \& Rahmani, B. (2009). Estimation of Saturation Percentage of Soil Using Multiple Regression, ANN and ANFIS Techniques. Computer and Information Science, 2(3), 127-136.

[2]. Abdulwahed, M. (2016). Modelling of sodium adsorption ratio of the soil using ANFIS. Journal Repository, 3(5), 21-34

[3]. Bektas, S \& Ozgan, E. (2010). Adaptive Neuro Fuzzy Inference System for Estimating Particle Diameter of Soils in Micro Structure for Varying Quantities of Sodium Hexametaphosphate. Scientific Research and Essays, 5, 782-789.

[4]. Bronick, C. J \& Lal, R. (2005). "Soil structure and management: a review". Geoderma,124(2), 3- 22.

[5]. Denmead, O. T \& Shaw, R. H. (2017). "Availability of soil water to plants as affected by soil Moisture content and meteorological conditions". Agronomy journal, 54(5), 385-390.

[6]. Dominati,E., Patterson, M \& Mackay, A. (2010). "A frame work for classifying and quantifying The natural capital and ecosystem services of soils". Ecological Economics, 69(9), 1858-1868

[7]. Hashemi, M. (2018). Predicting the effective stress parameter of unsaturated soils using ANFIS. Int. Journal of Computer Science, 4(6), 56-67

[8]. Jang, J.S.R., Sun, C.T \& Mitzutani, E. (1997). Neuro fuzzy and soft computing: a computational approach to learning and machine intelligence, prentice hall inc., upper saddle river USA, 8-33.

[9]. Mcbratney, A.B \& Odeh, I.O.A. (1997). Application of Fuzzy Sets in Soil Science: Fuzzy Logic, Fuzzy Measurements and Fuzzy Decisions. Geoderma, 77, 85-113.

[10]. Mokarram, M. (2017). Land suitability for wheat cultivation using ANFIS. Int. Journal of Computer Science, 8(4), 29-43

[11]. Ponge, J. F. (2015). "The soil as an ecosystem". Biology and Fertility of Soils, 51(6), 645-48.

[12]. Rahnema, H. (2018). Predicting the effective stress parameter of unsaturated soils using ANFIS. Int. Journal of C omputer Science and Telecommunication, 2(9), 87-99.

[13]. Saad, A., Mohamed,W., Mohamed,S \&Abdulwahed, A. (2014). Prediction of soil fraction (sand, silt and clay) in surface layer based on natural Radionuclides concentration in the soil using Adaptive neuro fuzzy inference system. Journal of soil science,4(7), 56-67.

[14]. Schlesinger, W. H \& Andrews, J. A. (2000). "Soil respiration and the global carbon cycle". Biogeochemistry,48(1), 7-20.

[15]. Sendren S \& Xu D (2007) Fuzzy logic applications in control theory and system biology. Journal of fuzzy system. 30(2),35-47

[16]. Sezer, A., Goktepe, B.A \& Altun, S. (2010). Adaptive Neuro-Fuzzy Approach for Sand Permeability Estimation. Environmental Engineering and Management Journal, 9(4), 231-238.

[17]. Suliman, A.S \& Post, D.F. (1988). Relationship between Soil Spectral Properties and Sand, Silt, and Clay Content of the Soils on the University of Arizona Maricopa Agricultural Centre. Proceedings of Hydrology and Water Resources in Arizona and the Southwest, 16 April 1988, Tucson, Arizona (Arizona-Nevada Academy of Science, Tucson Arizona), 18, 61-65.

[18]. Tiwari, A. (2017). A novel data mining based hybrid intrusion detection frame work. Journal of Information and computing science,9(3), 25-38

[19]. Torbert, H. A \& Wood, W. (1992). "Effect of soil compaction and water-filled pore space on soil Microbial activity and nitrogen losses".Communications in soil science and plant Analysis, 23(11), 1321-1331.

[20]. Torsvik, V \& Ovreas, L. (2002). "Microbial diversity and function in soil: from genes to Ecosystems". Current opinion in microbiology,5(3), $240-245$. 